\title{
Oficina integrada de geração de trabalho e renda: estratégia para formação de empreendimento econômico solidário*
}

\author{
Integrated workshop of work and income generation: \\ strategy for the formation of solidarity economical \\ enterprises
}

\author{
Isabela Aparecida de Oliveira Lussi ${ }^{1}$, Carolina da Silva Shiramizo ${ }^{2}$
}

http://dx.doi.org/10.11606/issn.2238-6149.v24i1p28-37

Lussi IAO, Shiramizo CS. Oficina integrada de geração de trabalho e renda: estratégia para formação de empreendimento econômico solidário. Rev Ter Ocup Univ São Paulo. 2013 jan./ abr:24(1):28-37.

RESUMO: A oficina integrada de geração de trabalho e renda foi composta por usuários de serviços da saúde mental e outros moradores residentes no território-alvo de um projeto realizado pela Incubadora Regional de Cooperativas Populares da UFSCar (INCOOP/UFSCar) que visava o desenvolvimento territorial de bairros periféricos no âmbito da economia solidária (ES). O estudo teve como objetivo conhecer as percepções das participantes da oficina sobre esta como estratégia para a formação de um empreendimento econômico solidário e compreender o que foi determinante para elas aceitarem trabalhar de acordo com os princípios da ES. Trata-se de um estudo de abordagem qualitativa. Para a coleta de dados utilizou-se entrevistas semiestruturadas que foram aplicadas com todas as participantes da oficina que permaneceram durante todo o trabalho, totalizando cinco pessoas. Os resultados apontam que a oficina propiciou o encaminhamento e a orientação das participantes e mostrou-se como espaço de inclusão de usuários da saúde mental. Dentre os motivos que levaram as participantes a permanecerem na oficina destaca-se a autogestão. Acredita-se que estudos desenvolvidos nesta direção possam fornecer subsídios para a elaboração de políticas públicas que fomentem tecnologias sociais que visem a inclusão social das pessoas em situação de desvantagem social.

DESCRITORES: Trabalho; Saúde mental; Reabilitação.
Lussi IAO, Shiramizo CS. Integrated workshop of work and income generation: strategy for the formation of solidarity economical enterprises. Rev Ter Ocup Univ São Paulo. 2013 jan./ abr.;24(1):28-37.

\begin{abstract}
The Integrated workshop of work and income generation was composed of users of mental health services and other residents living in the territory target of a project conducted by the Regional Incubator of Popular Cooperatives UFSCar (INCOOP / UFSCar). The study aimed to understand the perceptions of the participants of this workshop as a strategy for formation of solidary economical enterprise and understand what was important for them to accept work according to the principles of solidarity economy. This is a qualitative approach. For the data collection we used semi-structured interviews that were applied to all the participants of the workshop that remained throughout the work, totaling five people. The results indicate that the workshop provided the directing and the guidance of participants and showed as a space to inclusion of users of mental health. Among the reasons that led the participants to remain in the workshop highlights the self-management. It is believed that studies carried out in this direction can aid in the development of public policies that foster social technologies aimed at social inclusion of people who are social disadvantaged.
\end{abstract}

KEY WORDS: Work; Mental health; Rehabilitation.

\footnotetext{
* Trabalho oriundo de Pesquisa de Iniciação Científica com bolsa PIBITI/CNPq - UFSCar.

Os resultados deste estudo foram apresentados no XIX Congresso de Iniciação Científica da UFSCar, de 26 a 30 de setembro de 2011 e no XII Congresso Brasileiro de Terapia Ocupacional e IX Congresso Latino Americano de Terapia Ocupacional, realizado no período de 11 a 14 de outubro de 2011.

${ }^{1}$ Docente do Departamento de Terapia Ocupacional da Universidade Federal de São Carlos e do Programa de Pós-Graduação em Terapia Ocupacional da UFSCar. E-mail: belussi@ufscar.br

2 Terapeuta Ocupacional do CAPS II Infantil Cidade Ademar/São Paulo, SP. E-mail: carolshiramizo@gmail.com

Endereço para correspondência: Universidade Federal de São Carlos - Departamento de Terapia Ocupacional. Rodovia Washington Luís, km 235. São Carlos, SP. CEP: 13565-905.
} 


\section{INTRODUÇÃO}

$\mathrm{O}$ s vários séculos de predomínio do capitalismo geraram um modelo de desenvolvimento responsável pelo fomento das desigualdades, da exclusão social e da precarização das relações de trabalho ${ }^{13,22}$.

Os resultados do impacto desse sistema econômico, no qual a competição impera e a desigualdade é vista como consequência natural dentro do processo de polarização da sociedade, apontam para a necessidade de construção de uma "[...] outra economia para atender às demandas de uma sociedade mais exigente, técnica e intelectualmente mais qualificada. As necessidades de justiça, de respeito humano, de realizações materiais mais aperfeiçoadas se fazem sentir por todo o mundo"13 (p.10).

Neste sentido, deve-se considerar a economia solidária como uma alternativa, pois as suas experiências sinalizam traços de protagonismo dos sujeitos, alterando seu modo de vida e transformando-os em sujeitos econômicos, capazes de reter a riqueza que produzem e de incrementá-la gradualmente em si, a partir dos ativos materiais, intelectuais e relacionais que possuem e da exploração da sua capacidade de trabalho.

Segundo Singer ${ }^{24}$, a economia solidária é outro modo de produção, cujos princípios básicos são a propriedade coletiva ou associada do capital e o direito à liberdade individual. Ao serem aplicados, esses princípios geram a união de todos os que produzem, criando uma única classe de trabalhadores, tornando-os possuidores de capital por igual em cada cooperativa ou sociedade econômica, fugindo assim, da cultura materialista e instrumental e estabelecendo outra relação entre os seres humanos e a natureza.

Dentre os princípios da economia solidária pode-se destacar: 1) Autogestão, que se caracteriza pela participação igualitária de todos os cooperados, tanto nas decisões quanto nas divisões, gerando democracia; 2) Democracia; 3) Cooperação ao invés da competição; 4) Centralidade do ser humano, a importância é focalizada na pessoa e não no lucro; 5) Solidariedade; 6) Valorização da diversidade; 7) Emancipação; 8) Valorização do saber local, da identidade cultural e da tecnologia popular; 9) Valorização da aprendizagem e da formação; 10) Justiça social na produção, comercialização, consumo, financiamento e desenvolvimento tecnológico; 11) Sustentabilidade ambiental ${ }^{9}$.

Observa-se, de acordo com estes princípios, que a economia solidária focaliza a emancipação social individual e coletiva estimulando a formação contínua das pessoas o que, certamente, contribui para a organização política e reivindicação de direitos de cidadania dessas pessoas que se encontram excluídas socialmente. Além disso, há uma preocupação com a geração de trabalho e renda da população excluída do mercado de trabalho, porém, de forma harmoniosa com a natureza.

A economia solidária apresenta-se como uma alternativa de organização do trabalho oposta ao capitalismo, pois propõe um novo modo de produção e organização social, estimulando a solidariedade, a democracia e o respeito ao outro, à natureza e às diferenças, a autogestão, cooperação, promoção dos direitos humanos, possibilitando a abertura de caminhos para a inclusão social por meio do trabalho para pessoas que, por diversos motivos, se encontram em situação de exclusão social, como é o caso dos usuários dos serviços de saúde mental.

Em geral, os usuários dos serviços de saúde mental experimentam em suas trajetórias de vida um descrédito em relação às suas capacidades e potencialidades, sejam laborativas, relacionais ou de qualquer outra natureza. Isso pode acarretar uma situação de dependência econômica, subordinação e imobilização para conquista de seus direitos de cidadania. A participação dos usuários dos serviços de saúde mental no movimento da economia solidária, pelas características apresentadas anteriormente, pode ser um facilitador para a emancipação e inserção social dos mesmos.

A inserção social dos usuários dos serviços de saúde mental ocupa um lugar de destaque no processo da reforma psiquiátrica que é norteado pelo referencial da reabilitação psicossocial ${ }^{21}$.

A reabilitação psicossocial propõe a (re)construção do exercício de cidadania para os usuários dos serviços de saúde mental, não somente do ponto de vista dos direitos formais, mas também no sentido de construção de um espaço de negociação e troca, tanto materiais como afetivas e pessoais, por meio de uma rede de negociação que envolve profissionais da área, familiares, comunidade e atores envolvidos nos processos sociais. Nesta perspectiva o processo de reabilitação psicossocial é orientado por três eixos de participação e contratualidade dos sujeitos: habitat, rede social e trabalho ${ }^{23}$.

O primeiro eixo está referido à importância do direito à moradia, sobretudo, à importância do processo de apropriação da moradia e construção dos desejos e habilidades ligadas ao habitar.

O eixo rede social diz respeito à importância das trocas nas redes sociais e o papel da família, que deve ser envolvida no projeto de reabilitação. $\mathrm{O}$ eixo trabalho é apresentado como um recurso com grande potência para a inserção social, o qual produz sentido de vida, 
valores subjetivos e trocas materiais e afetivas. Portanto, a reabilitação psicossocial visa a ampliação dos espaços e das oportunidades de troca e negociação dos usuários da saúde mental ${ }^{23}$. As iniciativas de inclusão social por meio do trabalho buscam contribuir para a reabilitação psicossocial e econômica dos usuários da saúde mental.

As diretrizes da Política Nacional de Saúde Mental objetivam construir um lugar social efetivo para os usuários por meio de ações que ampliem sua autonomia e melhorem sua condição de vida ${ }^{7}$.

Considerando tais diretrizes o Governo Federal desenvolveu uma estratégia para a reabilitação e a inclusão de usuários da saúde mental no trabalho na perspectiva da economia solidária ${ }^{7}$.

Considera-se a Economia Solidária como uma estratégia positiva, pois esta, assim como a Reforma Psiquiátrica, pauta-se na construção de uma sociedade mais igualitária, inclusiva e solidária, na qual os leques de oportunidades aumentem, criando maiores espaços de interação e produção de vida ${ }^{25}$.

Da articulação entre os Ministérios da Saúde e do Trabalho e Emprego, surgiu o Grupo de Trabalho Saúde Mental e Economia Solidária que se empenhou na construção e implementação dessa política de inclusão ${ }^{8}$.

Esse grupo realizou um mapeamento das iniciativas e identificou como a maior dificuldade encontrada pelas experiências de geração de renda na área de saúde mental a fase de formação dos empreendimentos e, em seguida, a sua emancipação dos serviços de saúde mental. Neste sentido, as Incubadoras Tecnológicas de Cooperativas Populares (ITCPs), as delegacias regionais do trabalho (DRTs) e os fóruns de economia solidária têm se destacado no apoio aos grupos para que se tornem empreendimentos autogestionários $^{18}$.

A Incubadora Regional de Cooperativas Populares da Universidade Federal de São Carlos (INCOOP/UFSCar) (1) atua neste sentido. Desenvolve projetos direcionados a parcela da população excluída do mercado de trabalho ou inserida de forma precária.

O trabalho de intervenção da INCOOP considera nove condições essenciais para o processo de incubação:

1. Formação contínua e permanente para o cooperativismo;

2. Formação contínua e permanente para a autogestão como centralidade em todas as situações que envolvem o processo de incubação (na prática e não apenas em situações formais);

3. Caracterização dos envolvidos no processo de incubação (do grupo, condições de renda, cadeia produtiva, parcerias) para definição dos procedimentos de trabalho;

4. Estudos para definição de atividade econômica: estudo da viabilidade produtiva, exame da cadeia produtiva e do mercado;

5. Busca pela viabilidade econômica de maneira contínua e permanente;

6. Capacitação técnica para o serviço/produção ofertado pelo empreendimento;

7. Capacitar para a autonomia administrativa

8. Buscar a propriedade dos bens de produção;

9. Promover estatuto e regimento interno de maneira participativa, contemplando princípios da economia solidária e cooperativismo (buscando a consolidação de um processo mais preventivo para condutas favoráveis e menos punitivo) ${ }^{16}$.

Desde 2007, a INCOOP vem executando projeto que propõe a criação de um sistema integrado de empreendimentos econômicos solidários como condição para o desenvolvimento territorial de bairros de populações em situações de risco social e elegeu como alvo de suas ações dois bairros periféricos da cidade de São Carlos, que constituem bolsões de pobreza.

Uma das metas desse projeto está vinculada à Saúde Mental e visa a inclusão social de usuários de serviços de saúde mental residentes no território-alvo por meio do trabalho em empreendimentos econômicos solidários.

Em 2008, foi implantada uma oficina integrada de geração de trabalho e renda, formada por usuários de serviços de saúde mental e outros moradores do território que não se encontravam nesta condição. O objetivo da oficina era possibilitar a formação dos participantes em economia solidária e criar condições para que os participantes se organizassem de forma coletiva com vistas a formar um empreendimento econômico solidário (EES) ${ }^{17}$.

Durante todo o processo, o grupo, formado por sete mulheres e um homem foi acompanhado semanalmente por uma equipe de incubação composta por uma terapeuta ocupacional, uma psicóloga e uma estudante de terapia ocupacional. Nos encontros foram realizadas dinâmicas e discussões referentes às características de empreendimentos

(1) A INCOOP/UFSCar foi sucedida, no final de 2011, pelo Núcleo Multidisciplinar e Integrado de Estudos, Formação e Intervenção em Economia Solidária (NuMI-EcoSol/UFSCar). Porém, como este estudo foi realizado durante o ano de 2011, utilizaremos a denominação INCOOP/UFSCar. 
no âmbito da economia solidária, aos princípios do cooperativismo e da economia solidária, às alternativas para geração de trabalho coletivo e renda e ao método de incubação da INCOOP, sempre promovendo a participação ativa das pessoas.

Também foram realizadas discussões e experimentações de produtos escolhidos pelo grupo com vistas a definir sua atividade produtiva. Em seguida o grupo optou pela fabricação de produto de limpeza, pela apropriação da atividade por algumas participantes do grupo e também pela grande procura do produto na região ${ }^{17}$ Assim, o grupo iniciou o processo de formação de um EES pertencente à cadeia de produção da limpeza.

Cabe ressaltar a importância de se considerar a opinião dos atores sociais diretamente envolvidos com os processos de inclusão social pelo trabalho na proposição de políticas públicas voltadas à geração de trabalho e renda.

O presente estudo se propôs a contribuir neste sentido, uma vez que investigou as percepções das participantes da oficina integrada de geração de trabalho e renda sobre esta como estratégia para a formação de um empreendimento econômico solidário e tentou compreender o que foi determinante para as participantes aceitarem trabalhar de acordo com os princípios da economia solidária.

\section{Percurso Metodológico}

Trata-se de um estudo de caso transversal descritivo, que fez uso da abordagem qualitativa.

As metodologias de pesquisa qualitativa podem ser entendidas como aquelas que possibilitam a incorporação do significado e da intencionalidade inerentes aos atos e às relações humanas e sociais ${ }^{20}$.

Foram sujeitos do estudo as cinco participantes da oficina integrada de geração de trabalho e renda que participaram de todo o trabalho, incluindo a fase de implantação do empreendimento econômico solidário da cadeia de produção da limpeza. A coleta de dados foi realizada um ano após a finalização da oficina, durante um mês.

O projeto foi submetido ao Comitê de Ética em Pesquisa em Seres Humanos da UFSCar, sendo aprovado em 13/10/2010, sob o Protocolo: $n^{\circ}$ 0117.0.135.000-10, Parecer: no 367/2010. Após sua aprovação, iniciou-se o desenvolvimento do estudo.

Para a coleta de dados foi utilizada a técnica de entrevista devido a sua flexibilidade.

Foi escolhida a entrevista semi-estruturada, pois, combina questões estruturadas e abertas e o entrevistado pode discorrer sobre o tema, sem condições prefixadas pelo entrevistador ${ }^{20}$.

Para desenvolver as entrevistas, a aluna pesquisadora entrou em contato com as cinco participantes da oficina que participaram de todo o processo para apresentar o estudo, seus objetivos, os procedimentos de coleta de dados e convidá-las para participar. As cinco aceitaram participar e assinaram o Termo de Consentimento Livre e Esclarecido (TCLE). Após os esclarecimentos e assinatura do TCLE foi marcada a data para a realização das entrevistas.

A aplicação das entrevistas ocorreu em local e horário previamente combinados. Quatro participantes foram entrevistadas em suas residências e apenas uma foi entrevistada em seu local de trabalho.

Antes do início da entrevista, cada participante respondeu um protocolo de informações pessoais e profissionais, contendo dados sobre idade, sexo, estado civil, escolaridade e profissão. Para a realização da entrevista foi utilizado um roteiro como suporte, de modo que todas as entrevistadas puderam discorrer livremente sobre os mesmos temas.

O roteiro foi preparado baseado nos objetivos da pesquisa e em referencial bibliográfico da área e continha questões relacionadas ao interesse inicial das participantes em participar da oficina; às impressões e expectativas delas sobre a mesma; ao significado da oficina para elas; à opinião delas quanto a oficina como estratégia para a implantação de empreendimento econômico solidário; às afinidades ou não das participantes com os princípios da economia solidária; à característica integrada (ter a participação de usuários da saúde mental e outras pessoas que não se encontravam nesta condição) da oficina.

Visando a adequação do instrumento de coleta de dados foi realizado um estudo prévio com dois sujeitos antes da efetiva coleta

As entrevistas foram gravadas na íntegra, e foi elaborado um diário de campo no qual foram anotados todos os sinais de comunicação não verbal, como gestos, expressões faciais, entonações, enfim, todas as informações consideradas importantes para a apreensão e validação do que foi efetivamente dito.

Para a análise dos dados utilizou-se a técnica de Análise Temática proposta por Bardin², que implica em identificar os núcleos de sentido contidos na comunicação.

Para realização da análise todas as entrevistas foram transcritas em sua íntegra. Após, foram ordenadas junto aos protocolos de informações pessoais e profissionais e às anotações do diário de campo, de forma que cada participante tinha o conjunto de dados coletados.

Após tal ordenação foi feita a leitura exaustiva 
de cada uma das entrevistas junto às anotações do diário de campo, buscando uma apreensão global das mesmas, dos seus aspectos dinâmicos e interativos. Em seguida, buscou-se a identificação dos temas significativos ou das unidades de significação, utilizando os objetivos pré-estabelecidos como pano de fundo. Na sequência montou-se uma planilha com todos os temas identificados em cada uma das entrevistas.

Os temas que mais apareceram se referiam à positividade da experiência da oficina como estratégia na implantação de empreendimento econômico solidário, ao caráter inclusivo da oficina e ao desejo das participantes em libertar-se da relação de subordinação patrão - empregado e ter o próprio negócio.

A planilha permitiu a agregação dos temas identificando-se as seguintes categorias:

- Oficina Integrada de Geração de Trabalho e Renda: uma estratégia positiva.

- Oficina: espaço gerador de oportunidades e ferramenta para inclusão de usuários dos serviços de saúde mental.
- Sonhos e desejos: aspectos determinantes para a entrada e permanência das participantes na oficina.

A seguir serão apresentados os resultados da pesquisa de forma a caracterizar a população do estudo e a descrever as categorias de análise. Alguns depoimentos das participantes serão utilizados para explicitar os resultados descritos.

Os resultados serão discutidos à luz de referencial teórico da área da saúde mental e da economia solidária.

\section{RESULTADOS E DISCUSSÃO}

Os sujeitos da presente pesquisa foram todos os participantes da oficina integrada de geração de trabalho e renda que permaneceram durante todo o processo de trabalho, incluindo a fase de implantação do empreendimento econômico solidário pertencente à cadeia de produção da limpeza, totalizando cinco participantes.

O Quadro 1 mostra o perfil das participantes do estudo.

Quadro 1 - Perfil das participantes da oficina

\begin{tabular}{|c|c|c|c|c|c|c|}
\hline Participante & Idade & Estado civil & Escolaridade & Serviços realizados & Profissão & $\begin{array}{l}\text { Atividade remunerada que } \\
\text { exercia antes da oficina }\end{array}$ \\
\hline P1 & 61 & Casada & $8^{\mathrm{a}}$ série & Trabalho em fábrica & Do lar & Nenhuma \\
\hline $\mathbf{P 2}$ & 53 & Casada & $1^{\circ}$ ano do ginásio & $\begin{array}{l}\text { Açougue, Fábrica de } \\
\text { tapetes }\end{array}$ & Do lar & Nenhuma \\
\hline P3 & 18 & Solteira & $8^{a}$ série & $\begin{array}{l}\text { Cabelereira, manicure, } \\
\text { babá. }\end{array}$ & Cabelereira & Manicure e pedicure \\
\hline P4 & 48 & Casada & $4^{\mathrm{a}}$ série & $\begin{array}{l}\text { Empregada doméstica, } \\
\text { cozinheira, Buffet }\end{array}$ & $\begin{array}{l}\text { Empregada } \\
\text { doméstica }\end{array}$ & $\begin{array}{l}\text { Vendedora de produtos de } \\
\text { limpeza }\end{array}$ \\
\hline P5 & 55 & Casada & $4^{\mathrm{a}}$ série & Empregada doméstica & Do lar & Nenhuma \\
\hline
\end{tabular}

Das cinco participantes do estudo, todas são do sexo feminino com média de idade de 47 anos. Quanto ao estado civil, quatro são casadas e uma é solteira.

Em relação à formação escolar, a população foi composta por duas pessoas com ensino fundamental incompleto, duas com ensino fundamental completo e uma com ensino médio incompleto.

Em relação à experiência profissional, foi encontrada grande variedade de atividades.

Durante a realização da oficina, no ano de 2008, três das participantes não exerciam atividades remuneradas, uma participante trabalhava como manicure, porém, informalmente e uma participante vendia produtos de limpeza confeccionados na própria residência.
A seguir serão apresentados os resultados provenientes das entrevistas que passaram por análise temática.

\section{Oficina Integrada de Geração de Trabalho e Renda: uma Estratégia Positiva}

Foi possível identificar que a oficina propiciou o encaminhamento e a orientação das participantes, dados como necessários para que o grupo caminhasse em direção a formação do empreendimento econômico solidário.

Foi evidenciado que a realização da oficina criou oportunidade de discussão dos vários encaminhamentos que o grupo poderia ter e isso parece ter orientado o grupo 
em suas escolhas.

Nota-se também a construção de sentido referente ao trabalho que estava sendo estruturado pelas participantes juntamente com as equipes que acompanharam o processo, evidenciando a importância da assessoria das equipes, principalmente no que diz respeito à prática e aos princípios da economia solidária, que fez surgir no grupo dúvidas, incertezas, ansiedades e necessidade de apoio e incentivo.

\begin{abstract}
"Ah, uma dedicação porque tudo que eles faziam era em torno de ajudar o grupo né. A levar o grupo pra frente. Então achei que a participação deles era cabivel ao grupo." (P3)
\end{abstract}

Argumenta-se que as equipes de incubação devem ser capacitadas e devem esclarecer às pessoas envolvidas no empreendimento que estão preparadas para assessorá-los quando necessário, envolvendo-se com o trabalho do grupo e com a comunidade, como revela o depoimento acima ao apontar que as equipes se esforçavam para assessorar o bairro, dando mais segurança em relação aos resultados do empreendimento.

Percebeu-se que este movimento da equipe de incubação é importante para o sucesso de um empreendimento, pois é na equipe que as pessoas depositam seus sonhos, medos e desejos e cabe a ela dar subsídios e segurança para as mesmas, fazendo com que o grupo consiga, de forma coletiva, colocar os planos em prática, dando indícios que sempre que preciso darão suporte, mas ao mesmo tempo capacitando-os para a autogestão.

De acordo com $\mathrm{Cruz}^{14}$ o processo de incubação de empreendimentos econômicos solidários é um processo pedagógico que se realiza por meio de trocas entre dois saberes que se produzem em esferas distintas da vida social. Por um lado,

[...] de um saber popular construído pela vida: em periferias de cidades e em zonas rurais diferentes; de formações econômicas e sociais distintas; com hábitos ou tradições marcadas pelo enraizamento, ou justamente ao contrário, pelo desenraizamento e pela desterritorialização; fundadas sobre diferentes tipos de solidariedade e de violência; etc. E de outro lado, por um saber institucionalmente produzido e reproduzido: marcado por regras, procedimentos [...] e hierarquias rigorosas, em seu processo de acumulação e de reprodução; social e economicamente instrumentalizado (não-neutro); que se pretende articulado mundialmente, acima de diferenças culturais, históricas e sociais, mas que entrelaça uma extensa e nodosa rede de poder; e que, com (e por) tudo isto, ganha legitimidade como portador de uma eficácia relativa no campo da ação $\operatorname{social}^{14}$ (p. 2-3).
O autor aponta a existência de uma diversidade de metodologias de incubação adotadas pelas ITCPs que se justificam pelas diferenças de condições institucionais em que se criaram e em que operam. No entanto todas as metodologias se fundamentam nos princípios do cooperativismo, da propriedade coletiva, da construção do conhecimento compartilhado, da democracia e da solidariedade com o objetivo de que os grupos alcancem a autogestão.

De acordo com o método de trabalho da INCOOP/ UFSCar, o processo de incubação deve ser realizado pela equipe responsável pela cadeia na qual a atividade produtiva do empreendimento está compreendida, no caso deste grupo, a cadeia de limpeza ${ }^{26}$. Portanto, durante o desenvolvimento da oficina, o grupo foi assessorado por duas equipes que, apesar de distintas, trabalharam juntas durante o período transitório ${ }^{17}$.

\section{Oficina: Espaço Gerador de Oportunidades e Ferramenta para Inclusão de Usuários dos Serviços de Saúde Mental}

Para a discussão desta categoria, é importante resgatar o processo da reforma psiquiátrica em curso no Brasil.

A reforma psiquiátrica é um processo político de transformação social que nasceu da articulação de trabalhadores do campo da saúde mental com outros atores sociais como, familiares dos usuários de serviços de saúde mental, universitários, intelectuais etc., inspirados pelo movimento de reforma psiquiátrica italiano, o qual colocou em questão não apenas a instituição hospitalar psiquiátrica, mas também o saber psiquiátrico e o conceito de doença mental, abolindo totalmente o hospital psiquiátrico ${ }^{1}$.

No cenário nacional a Lei $10.216^{6}$, redirecionou o modelo assistencial em saúde mental, porém, não garantiu a extinção total dos hospitais psiquiátricos. No entanto, os de grande porte estão sendo substituídos progressivamente.

A reforma psiquiátrica se configura como um modelo que procura restabelecer os direitos e a cidadania do usuário dos serviços de saúde mental. Este processo impulsionou a constituição da atual Política Nacional de Saúde Mental, que, com base na Lei 10.216, busca consolidar e ampliar o modelo de atenção à saúde mental de base comunitária e territorial. Para tal, instituiu a Rede de Atenção Psicossocial que tem como finalidade a criação, ampliação e articulação de atenção à saúde de pessoas com transtorno mental e transtornos decorrentes do uso de crack, álcool e outras $\operatorname{drogas}^{10}$.

Um dos objetivos da Rede é a promoção da reabilitação e a reinserção dos usuários de serviços de saúde 
mental na sociedade, por meio de iniciativas de trabalho, renda e moradia solidária ${ }^{10}$, que é norteada pelo referencial da reabilitação psicossocial. Desta forma, as iniciativas de geração trabalho e renda, os empreendimentos econômicos solidários e as cooperativas sociais são estimulados como estratégias de reabilitação psicossocial da Rede ${ }^{10}$, inclusive com incentivo financeiro por meio da Portaria $\mathrm{N}^{\mathrm{o}} 132^{11}$.

Estas conquistas se devem à parceria entre o Ministério da Saúde e a Secretaria Nacional de Economia Solidária (SENAES) do Ministério do Trabalho e Emprego, já citada anteriormente neste texto, que estabeleceu diretrizes para o Programa de Inclusão Social pelo Trabalho ${ }^{11}$.

Por empreendimentos econômicos solidários compreendem-se as "diversas modalidades de organização econômica, originadas da livre associação dos trabalhadores, com princípios de autogestão, cooperação, eficiência e viabilidade. Aglutinando indivíduos excluídos do mercado de trabalho $[\ldots] "$ (p. 135) ${ }^{15}$.

Considerando esses pressupostos, acredita-se que a escolha pela economia solidária para a inserção laboral de pessoas em situação de exclusão social, com destaque para os usuários dos serviços de saúde mental, pode ser uma alternativa eficaz.

A oficina de geração de trabalho e renda mostrouse como um espaço de inclusão onde os usuários puderam exercer novos papéis e relacionar-se com diversas pessoas em situações de igualdade, respeito e solidariedade, além de possibilitar a abertura de caminhos para a inclusão social por meio do trabalho.

Por ser criada com base nos princípios da economia solidária, a oficina apresentou-se como um espaço potencial para a inclusão, já que a economia solidária tem como objetivo reverter e superar a economia capitalista, que tem como determinantes o capital, o individualismo e a competição. Ao invés disso, busca “construir um exercício de poder compartilhado, de relações sociais e de cooperação entre os trabalhadores [...] vivenciando outra forma de organização do trabalho e de sociedade" (p. 59).

Saraceno $^{23}$ aponta que é necessário encontrar uma nova maneira de enfrentamento do problema da relação entre trabalho e transtornos mentais "a partir de um ponto de vista totalmente alternativo, que permita uma reviravolta da lógica [...]", pois somente assim a idéia supersimplificada e idealizada do papel do trabalho sobre a saúde mental será superada (p. 133).

Percebe-se então o potencial da economia solidária para inclusão dos usuários dos serviços de saúde mental no trabalho, devido a sua característica de alternativa econômica, ética e política, que objetiva a mudança das relações sociais e a valorização dos sujeitos ${ }^{25}$.

\section{Sonhos e Desejos: Aspectos Determinantes para a Entrada e Permanência das Participantes na Oficina}

O presente estudo investigou os principais motivos que levaram as participantes da oficina a permanecerem na mesma até a fase de implantação do empreendimento econômico solidário. Dentre os motivos estão a autogestão, a perspectiva de renda e a possibilidade de trabalho, com destaque para a autogestão.

A partir do levantamento da Economia Solidária, realizado pelo Ministério do trabalho e Emprego, esses são motivos comuns que levam a constituição de iniciativas solidárias no Brasil.

Foi possível perceber nos relatos das participantes o desejo pela autogestão, como mostram os depoimentos abaixo.

\begin{abstract}
"Eu achei que seria uma coisa boa trabalhar numa coisa que era sua, que não tinha assim patrão que tá ali em cima da gente, você trabalhar por conta numa coisa que seria da gente, que a gente que ia fazer, a gente que ia tomar conta, a gente que ia formar tudo, o trabalho tudo". (P1)

"Tudo que eu queria, assim, trabalhar por conta, assim, fazer alguma coisa, assim, por conta. Conta assim, que eu pudesse sai de trabalha pros outros, de ser empregada. (...) eu achei bom porque a gente não ia ter patrão né, a gente ia trabalhá pra gente mesmo, e a chance de outras pessoas participarem né, e também assim, pessoas igual eu que lutavam pra ser independente de patrão". (P4)
\end{abstract}

Os depoimentos das participantes explicitam o desejo que têm em libertar-se da relação de subordinação patrão - empregado, e experimentar um processo autogestionário. Segundo Barbieri et al. ${ }^{3}$, a autogestão, é:

A gestão que consiste na autonomia da coletividade dos membros da empresa de decidir sobre os destinos, os processos e os resultados do trabalho. Suas idéias gerais são: fim do assalariamento, organização do trabalho com base na gestão democrática, eliminação da hierarquia e decisões tomadas por democracia direta (p. 17).

Em estudo sobre saúde mental e economia solidária, Barfknecht et al. ${ }^{4}$ associam o modelo hegemônico de trabalho às relações sociais precárias, ao incremento do individualismo, à alienação e a precarização das relações trabalhistas, que retiram garantias e proteções dos trabalhadores, criando ambientes precários tanto física, como psiquicamente.

Mesmo diante de situações precárias de assalariamento, o trabalho assalariado ainda é visto com 
muito valor pelos trabalhadores, pois, cria a sensação de segurança ainda que os submeta a condições de subordinação social.

Devido a esses paradoxos do mundo do trabalho, um significativo número de trabalhadores está procurando alternativas ao modelo capitalista de geração de trabalho e renda, como a Economia Solidária.

A Economia Solidária é compreendida pelo SIES (Sistema Nacional de Informações em Economia Solidária) como "o conjunto de atividades econômicas - de produção, distribuição, consumo, poupança e crédito - organizadas e realizadas solidariamente por trabalhadores e trabalhadoras sob a forma coletiva e autogestionária"8 (p. 11). Destacamse como princípios norteadores quatro importantes características: autogestão, solidariedade, cooperação e viabilidade econômica.

Nesta perspectiva, a autogestão é vista como o exercício de práticas participativas "nos processos de trabalho, nas definições estratégicas e cotidianas dos empreendimentos, na direção e coordenação das ações nos seus diversos graus e interesses" (p. 12).

Por demandar caráter participativo nos processos de trabalho, a autogestão pode ser considerada um exercício de poder compartilhado que leva seus trabalhadores a tomarem decisões de forma coletiva e participativa, incentivandoos a exercer voz ativa. Esta é uma das características que difere um empreendimento solidário de um capitalista, pois coloca os trabalhadores como gestores efetivos do processo de trabalho ${ }^{5}$.

Além de mostrar-se como alternativa favorável para a superação das relações subordinadas de trabalho, a autogestão apresenta-se como uma forma de emancipação dos sujeitos e retomada das relações sociais de forma mais humanizada e coletivizada. Portanto, o anseio de trabalhar em algo de propriedade coletiva desperta um forte desejo em muitos trabalhadores assalariados, porém, este pode vir acompanhado de outros sentimentos, como medo e insegurança.

Neste sentido, a formação permanente em Economia Solidária das pessoas que compõem um empreendimento é premente, pois capacita os indivíduos a atuarem de acordo com métodos de trabalho baseados na solidariedade, na cooperação e na autogestão, tornando o processo de trabalho mais humanizado, democrático e significativo.

Também identificou-se no estudo, que as participantes obtiveram benefícios secundários advindos da oficina integrada de geração de trabalho e renda.

As participantes apontaram a oportunidade de novas experiências e aprendizado promovidos pela oficina, mostrando que além do objetivo primário de criar um espaço integrado entre usuários da saúde mental moradores do território e outros moradores que não se encontram nesta condição, a fim de introduzi-los aos princípios da Economia Solidária visando a formação de um empreendimento, a oficina teve ainda um caráter instrutivo e inspirador para essas pessoas, mostrando novas possibilidades e caminhos para o fazer.

Acredita-se que por ser baseada nos princípios da autogestão, coletividade e cooperação, a experiência exigiu das participantes posturas mais ativas, estimulando-as a dar opinião, contribuir nas decisões e na resolução de problemas que surgiam durante o processo. Esta postura exigida cria ambiente e oportunidades para o aprendizado constante das integrantes.

Por ter um caráter pedagógico, a Economia Solidária propicia a seus praticantes novos conteúdos e maneiras de relacioná-los com o seu cotidiano. Ao participarem ativamente do processo de criação de um empreendimento, as participantes vivenciaram etapas de trabalho até então desconhecidas para elas. O contato com o novo pode ter levado-as a pensar sobre possibilidades alternativas, fazendo com que desejos surgissem a partir destas descobertas e as experiências se ampliassem, originando aprendizado e novas possibilidades.

\section{CONSIDERAÇÕES FINAIS}

O presente estudo teve como objetivo conhecer as percepções das participantes da oficina integrada de geração de trabalho e renda sobre esta como estratégia para a formação de um EES e compreender o que foi determinante para elas aceitarem trabalhar de acordo com os princípios da economia solidária.

Avalia-se que os objetivos do estudo foram atingidos, porém, identificou-se dificuldade das participantes durante as entrevistas em retomarem os conteúdos vividos no período da oficina para emitirem suas opiniões. Argumentase que tal dificuldade relaciona-se com o distanciamento entre o período em que a coleta de dados foi realizada e o período em que a oficina ocorreu, ou seja, a coleta foi realizada um ano após o encerramento da oficina. Considerase que este fato comprometeu o conteúdo e aprofundamento das respostas das participantes.

A partir da análise das entrevistas realizadas foi possível identificar que a oficina foi avaliada positivamente pelas participantes, mostrando-se uma estratégia eficaz para a estruturação do empreendimento, pois disponibilizou suporte técnico para a formação em Economia Solidária, além de subsídio para outras questões que surgiram ao longo do caminho trilhado pelo grupo. 
Nesta perspectiva é importante ressaltar a ênfase atribuída pelas participantes à assessoria qualificada das equipes de incubação durante o processo, principalmente no que diz respeito à formação em Economia Solidária, trocando e construindo saberes com as cooperadas e incentivando-as e preparando-as para a autogestão.

A oficina, segundo as participantes, mostrouse como um espaço de criação de novos laços, trocas, amizades e conquistas atingidas. Acredita-se que isto foi possibilitado pelas características da Economia Solidária, que procura desconstruir o ambiente de competição e individualismo para desenvolver o pensamento coletivo e solidário, colocando os trabalhadores lado a lado como parceiros na construção de um empreendimento coletivo, e não na situação de rivais lutando para garantir um posto

\section{REFERÊNCIAS}

1. Amarante PDC, organizador. Loucos pela vida: trajetórias da reforma psiquiátrica no Brasil. Rio de Janeiro: SDE/ ENSP; 1995.

2. Bardin L. Análise de conteúdo. Lisboa: Edições 70; 1994.

3. Barvieri L, Rufino S, Núcleo de Gestão - ITCP/USP. A gestão da autogestão nas cooperativas. In: Mello SL, organizador. Economia solidária e autogestão: encontros internacionais. São Paulo: NESOL-USP, ITCP-USP, PW; 2005. p.17-24.

4. Barfknecht KS, Merlo ARC, Nardi H. Ca. Saúde mental e economia solidária: análise das relações de trabalho em uma cooperativa de confecção de Porto Alegre. Psicol Soc (Porto Alegre). 2006;18(2) [citado 4 ago. 2011]. Disponível em: http://www.scielo.br/scielo.php?script=sci_arttext\&pid=S0 $10271822006000200008 \& \operatorname{lng}=$ en\&nrm=iso $>$.

5. Beatriz MZ. Os sentidos da economia solidária: os caminhos da construção da autonomia coletiva e organizativa [Tese]. São Paulo: Pontifícia Universidade Católica de São Paulo; 2007.

6. Brasil. Lei n ${ }^{\circ} 10.216$, de 06 de abril de 2001. Dispõe sobre a proteção e os direitos das pessoas portadoras de transtornos mentais e redireciona o modelo assistencial em saúde mental [citado 7 abr. 2013]. Disponível em: http://www.planalto.gov. br/ccivil_03/leis/leis_2001/110216.htm.

7. Brasil. Ministério da Saúde. Secretaria de Atenção à Saúde. Departamento de Ações Programáticas Estratégicas. Saúde de trabalho.

O estudo também identificou a oficina como espaço de inserção de usuários dos serviços de saúde mental pelo trabalho.

Como motivos determinantes para a permanência das participantes na oficina foram encontrados a autogestão, a perspectiva de renda e a possibilidade de trabalho.

O estudo evidenciou que a Economia Solidária é uma alternativa possível para a inserção social das pessoas que se encontram excluídas. Estes caminhos precisam ser construídos e aperfeiçoados para que a inclusão se concretize, não só dos usuários da saúde mental, mas de todas as pessoas que, por diversos motivos, encontram-se excluídas do mundo do trabalho, e consequentemente, da sociedade.

mental e economia solidária: inclusão social pelo trabalho. Brasília: Editora do Ministério da Saúde; 2005.

8. Brasil. Ministério da Saúde. Ministério do Trabalho e Emprego. Relatório final do grupo de trabalho saúde mental e economia solidária. Brasília, DF: SAS, DAPE, CSM, SENAES; 2006.

9. Brasil. Ministério do Trabalho e Emprego. Economia solidária: a outra economia acontece: cartilha da campanha nacional de mobilização social. Brasília, DF: MET, SENAES, FBES; 2007.

10. Brasil. Portaria $\mathrm{N}^{\circ} 3.088$, de 23 de dezembro de 2011. Institui a Rede de Atenção Psicossocial para pessoas com sofrimento ou transtorno mental e com necessidades decorrentes do uso de crack, álcool e outras drogas, no âmbito do Sistema Único de Saúde (SUS) [citado 7 abr. 2013]. Disponível em: http://bvsms.saude.gov.br/bvs/saudelegis/ gm/2011/prt3088_23_12_2011_rep.html.

11. Brasil. Portaria $N^{\circ} 132$, de 26 de janeiro de 2012. Institui incentivo financeiro de custeio para desenvolvimento do componente Reabilitação Psicossocial da Rede de Atenção Psicossocial do Sistema Único de Saúde (SUS) [citado 8 abr. 2013]. Disponível em: http://bvsms.saude.gov.br/bvs/ saudelegis/gm/2012/prt0132_26_01_2012.html.

12. Brasil. Ministério da Saúde. Saúde mental em dados. Inf eletrônico. Brasília, DF: SAS/DAPES; 2012 [citado 8 abr. 2013]. Disponível em: http://portal.saude.gov.br/portal/ arquivos/pdf/mentaldados10.pdf. 
13. Cattani AD. A outra economia: os conceitos essenciais. In: Cattani AD, organizador. A outra economia. Porto Alegre: Veraz Editores; 2003. p.9-14.

14. Cruz A. Para construir uma pauta que nos ajude a pensar uma metodologia da incubação. Contribuição à metodologia do encontro nacional da pesquisa incubadoras - projeto Unitrabalho/ICCO - 2002 [citado 20 ago. 2011]. Disponível em: http://www.itcp.usp.br/drupal/node/251.

15. Gaiger LI. Empreendimentos econômicos solidários. In: Cattani D, organizador. A outra economia. Porto Alegre: Veraz Editores; 2003. p.135-42.

16. Incubadora Regional de Cooperativas Populares [citado 20 ago. 2011]. Disponível em: http://www.incoop.ufscar.br/ pasta/metodo-de-incubacao-da-incoop.

17. Lussi IAO. Implantação de piloto de oficina integrada de geração de trabalho e renda. São Carlos: DTO/UFSCar; 2009. (Relatório Projeto de Extensão).

18. Martins RCA. Saúde mental e economia solidária: construção democrática e participativa de políticas públicas de inclusão social e econômica. In: Cortegoso AL, Lucas MG, organizadores. Psicologia e economia solidária: interfaces e perspectivas. São Paulo: Casa do Psicólogo; 2008. p.245-62.

19. Minayo MCS. O desafio do conhecimento: pesquisa qualitativa em saúde. 7a ed. São Paulo: Hucitec/Abrasco; 2000 .

20. Pitta AMF, organizador. Reabilitação psicossocial no Brasil. São Paulo: Hucitec; 1996.

21. Santos BS, organizador. Produzir para viver: os caminhos da produção não capitalista. Rio de Janeiro: Civilização Brasileira; 2002.

22. Saraceno B. A Reabilitação como cidadania. In: Libertando identidades: da reabilitação psicossocial à cidadania possível. Belo Horizonte: Te Corá Editora/ Instituto Franco Basaglia; 1999.

23. Singer P. Introdução a economia solidária. São Paulo: Ed. Fundação Perseu Abramo; 2002.

24. Singer P. Saúde mental e economia solidária. In: Brasil. Ministério da Saúde. Secretaria de Atenção à Saúde. Departamento de Ações Programáticas Estratégicas. Saúde mental e economia solidária: inclusão social pelo trabalho. Brasília: Editora do Ministério da Saúde; 2005.

25. Zanin M, et al. Proposição de diretrizes para políticas públicas em economia solidária como condição para desenvolvimento de território urbano: caso Jardins Gonzaga e Monte Carlo - São Carlos - SP. São Carlos: INCOOP/UFSCar; 2008. (Relatório técnico, FAPESP no. 2007/55393-6). 